UNIVERSIDADE ESTADUAL DE FEIRA DE SANTANA

Autorizada pelo Decreto Federal $n^{\circ} 77.496$ de 27/04/76

Recredenciamento pelo Decreto $n^{\circ} 17.228$ de 25/11/2016

PPPG

PRÓ-REITORIA DE PESQUISA E PÓS-GRADUAÇÃO

COORDENAÇÃO DE INICIAÇÃO CIENTÍFICA

XXIII SEMINÁRIO DE INICIACÃO CIENTÍFICA DA UEFS

SEMANA NACIONAL DE CIENTÍFICA E TECNOLÓGICA - 2020

\title{
CARACTERÍSTICAS DE MULHERES QUE REALIZARAM MAMOGRAFIA EM UM HOSPITAL FILANTRÓPICO DE UMA CIDADE DO INTERIOR DA BAHIA
}

Tâmara Juliana Evangelista Lima ${ }^{1}$; Rosana Oliveira de Melo ${ }^{2}$

1. Bolsista PROBIC/UEFS, Graduando em Enfermagem, Universidade Estadual de Feira de Santana, e-mail: julianalima1231@outlook.com

2. Orientador, Departamento de Saúde, Universidade Estadual de Feira de Santana, e-mail: rosanaenfmelo@gmail.com

PALAVRAS-CHAVE: Mulher; Vulvovaginite; Saúde da Mulher.

\section{INTRODUÇÃO}

O corrimento vaginal é uma alteração comum, caracterizado pela eliminação de qualquer fluxo proveniente da vagina (Brasil, 2015). Existem dois tipos de fluxo vaginal, o fisiológico e o de caráter patológico, sendo o mais comum os sexualmente transmissíveis Fonseca et al. (2017).

As patologias mais comuns encontradas em mulheres em idade reprodutiva, e que causam corrimentos vaginais são: a candidíase vulvovaginal, a vaginose bacteriana e a tricomoníase. Dentre estas, com exceção da tricomoníase que é uma IST, as demais patologias são consideradas infecções do trato reprodutivo Fonseca et al. (2017).

Nesse contexto, é importante para a saúde da população feminina, que os profissionais da saúde, nesse caso aqui da Enfermagem, possam atuar de forma integral. Dessa forma, mediante os cuidados prestados, a mulher terá a oportunidade de fazer o seu acompanhamento rotineiro e ser orientada quanto à prevenção de infecções do trato reprodutivo, bem como realizar o tratamento correto. Diante do exposto, objetivou-se conhecer os saberes de mulheres com corrimentos vaginais acerca da prevenção, transmissão, diagnóstico e tratamento dessas infecções.

\section{MATERIAL E MÉTODOS}

Trata-se de uma pesquisa descritiva exploratória, de caráter qualitativo, recorte da pesquisa de Iniciação Científica "Saberes de mulheres com corrimentos vaginais 
atendidas em um centro de referência de uma cidade do interior da Bahia. Esta integra um projeto maior intitulado "Atenção à saúde da mulher nos serviços públicos do município de Feira de Santana - Ba”. Aprovado pelo Comitê de Ética em Pesquisa (CEP) da Universidade Estadual de Feira de Santana (UEFS), sob o parecer no 1327 867, emenda $\mathrm{n}^{\circ} 6$ Moreira \& Melo (2015).

O estudo foi realizado no Centro Municipal de Prevenção ao Câncer (CMPC), localizado na Bahia. Este dispõe de uma equipe multiprofissional habilitada a atender a população, composta por: Mastologista, Ginecologista, Oncologista, Urologista, Enfermeiro, Psicólogo, Assistente Social e Biomédico. Os dados do estudo foram coletados através da técnica de entrevista semi-estruturada, realizada com as mulheres atendidas no CMPC, no período de Janeiro a Fevereiro do presente ano, e seguiu os princípios da resolução 466/2012. coletados foram analisados por meio da Análise de Conteúdo de Bardin (Bardin, 2016).

\section{RESULTADOS E DISCUSSÃO}

Participaram do estudo três mulheres, admitidas em um centro de prevenção ao câncer. Todas possuíam histórico de corrimento vaginal. A idade das mulheres variou em um intervalo de 25 a 31 anos, adultas jovens, houve predominância de solteiras, em idade reprodutiva, com vida sexualmente ativa, com renda per capita que não ultrapassou um salário mínimo. Os dados do estudo possibilitaram descrevem os saberes de mulheres acerca do surgimento, prevenção e tratamento dos corrimentos vaginais.

A secreção vaginal é uma resposta fisiológica do organismo feminino. Quando não existe processo patológico envolvido, a secreção vaginal apresenta-se na coloração transparente ou branca Oliveira et al. (2015). Já as manifestações clínicas mais comuns dos corrimentos patológicos são: corrimento abundante, amarelado ou amarelo esverdeado ou acinzentado, prurido e/ou irritação da vulva (Brasil, 2015).

Ao serem questionadas como surgiu o corrimento as entrevistadas relataram:

[...] minha mãe disse que eu sempre tive desde pequena, que eu sempre tive corrimento vaginal, mas assim, na adolescência teve fases de vir muito, mais agora na vida adulta diminuiu. Hoje em dia não tive mais corrimento não, a não ser que eu passe o dia todo com calça jeans ou demore muito tempo pra tomar banho (P01). 
[...] geralmente depois de alguma relação sexual ou quando eu fico muito tempo de calça, passo o dia todo de calça trabalhando, aí fica (P02).

[...] começou uma coceira. Coçava. Não sei assim. Não sei bem (P03).

Desta forma, é preciso estabelecer diagnósticos, através das informações coletadas nas consultas ginecológicas, além da avaliação do corrimento através do exame especular.

Os corrimentos vaginais possuem características distintas, o que difere um do outro. Dessa forma, quando questionadas sobre o que faziam para prevenir o surgimento dos corrimentos as participantes relataram:

[...] Bom, eu cresci assim achando que o corpo ele responde a forma que ele está sendo tratado, por exemplo, o corrimento deve vir de alguma coisa dentro do corpo que não está correto, alguma infecção, eu não sei do que se trata. Então, se está tendo corrimento é porque alguma coisa interna não está bem, né? (Ficou pensativa) a mulher precisa ter higiene? Procurar um médico, não sei? Hum..., usar calcinha de algodão talvez, não sei (P01).

[...] Com certeza. Eu procuro um médico (P02).

Os hábitos de higiene e cuidados diários com a genitália feminina são fatores que podem influenciar o aparecimento das vulvovaginites. No que diz respeito a utilização de algum método de barreira, podemos observar que duas mulheres relataram não fazer uso. Uma delas já teve IST e atualmente tem relação homoafetiva, apesar de relatar o uso do preservativo com parceiros do sexo masculino.

[...] hoje mais não, porque mantenho relação com mulher. Mas, nas outras, sim. Só com um ex-namorado, mas o resto eu usava camisinha (P02).

[...] Não. Não gosto. Já fui orientada e mesmo assim não uso (P03).

O uso do preservativo é de suma importância, pois além de prevenir a gravidez, é o método de barreira mais eficaz para a prevenção de IST.

Para refletir sobre o processo de saúde e doença das mulheres, é preciso analisar o caminho percorrido quando são acometidas por alguma patologia. Esse caminho pode iniciar-se a partir da busca pela assistência à saúde, seja para prevenção ou tratamento (Pinho \& Pereira, 2012). O tratamento dependerá da comprovação da infecção. No 
geral, as infecções são tratadas com medicamentos de aplicação local em forma de creme vaginal, gel vaginal ou comprimidos (Brasil, 2015).

Quando questionadas sobre o tratamento dos corrimentos vaginais elas responderam:

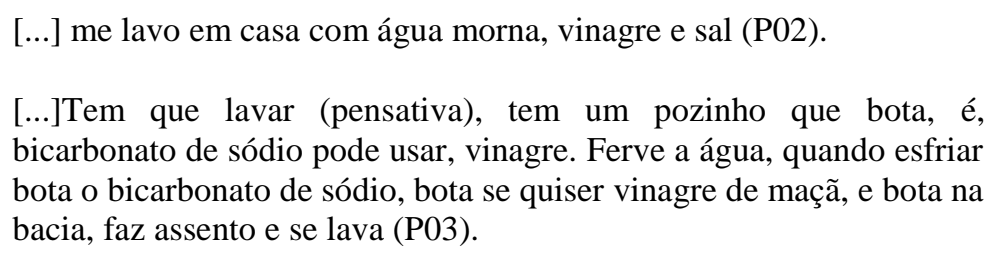

A entrevista P03 ainda diz:

[...] Falei com a mulher que trabalha no postinho, a assistente. E aí falei com ela e ela mandou eu tomar um comprimido que é dose única. Mas melhorou e voltou de novo, aí eu tive que comprar uma pomada que eu vi passando na televisão..., aí não tive mais (P03).

Dentre as falas das entrevistadas percebe-se que elas, utilizaram o método não convencional, como o uso do bicarbonato de sódio, como também a automedicação, para minimizar ou tratar suas infecções.

Dentre as muitas utilidades do bicarbonato de sódio está o seu potencial de aliviar os sintomas da candidíase. O bicarbonato é básico e por isso alivia os sintomas, pois a candidíase se desenvolve no meio ácido Júnior et al. (2011), havendo assim um equilíbrio ácido básico.

A prática de automedicação é algo que acontece frequentemente em todo o mundo. Pela sua própria definição, a noção de automedicação, é o ato de usar medicamentos sem prescrição médica (Musial, Dutra \& Becker, 2007).

\section{CONSIDERAÇÕES FINAIS}

De acordo com os resultados deste estudo, deve-se considerar que as características clínicas do corrimento vaginal de origem patológica, de causa sexualmente transmissível ou pela desregulação da flora vaginal foi algo presente nas mulheres do estudo. É importante estabelecer a causa do corrimento vaginal, para que o tratamento seja adequado. Os profissionais de saúde tem papel fundamental no aconselhamento e orientação destas pacientes e deve oportunizar o momento das consultas para discutir também sobre o surgimento, transmissão e a prevenção dessas patologias. 


\section{REFERÊNCIAS}

BARDIN, L. 2016. Análise de conteúdo. São Paulo: Edições 70.

BRASIL. 2015 [online] Protocolo Clínico e Diretrizes Terapêuticas Infecções Sexualmente Transmissíveis. Homepage:

http://conitec.gov.br/images/Consultas/Relatorios/2015/Relatorio_PCDT_IST_CP.pdf.

FONSECA, T. M. V.; et al. 2017. Corrimento vaginal referido entre gestantes em localidade urbana no Sul do Brasil: prevalência e fatores associados. Cad. Saúde Pública, Rio de Janeiro, v.24, n. 3, p. 558-566. Homepage: https://www.scielosp.org/pdf/csp/2008.v24n3/558-566/pt.

JÚNIOR, A. G; GRIGOLETO, A. R. L; FREGONEZI, P. A. G. 2014. Candidíase Vaginal: uma questão de educação em saúde/Vaginal. Brazilian Journal of Health, v. 2, n. 2. Homepage: http://inseer.ibict.br/bjh/index.php/bjh/article/view/87.

MOREIRA, R. de C. R.; MELO, R.O. PARECER DE APROVAÇÃO DO COMITÊ DE ÉTICA do projeto de pesquisa“Atenção à saúde da mulher nos serviços públicos do município de Feira de Santana - Ba. 2015.

MUSIAL, D. C.; DUTRA, J. S.; BECKER, T. C. A. 2007. A automedicação entre os brasileiros. Rev. Saúde e Biol., v. 2, n. 2, p. 5-8. Homepage:

file:///C:/Users/User/Downloads/85-236-1-PB.pdf.

OLIVEIRA, A. W.; et al. 2016. Prática de enfermagem na abordagem sindrômica de pacientes com queixa de corrimento vaginal. Journal of Nursing UFPE/Revista de Enfermagem UFPE, v. 10, n. 6; Pernambuco. Homepage:

file:///C:/Users/User/Downloads/11225-25242-1-PB.pdf.

PINHO, P. A; PEREIRA, P. P. G. 2012. Itinerários terapêuticos: trajetórias entrecruzadas na busca por cuidados. Interface (Botucatu), v.16, n.4. Homepage:

https://www.scielo.br/scielo.php?pid=S1414-32832012005000026\&script=sci_arttext. 